Document downloaded from:

http://hdl.handle.net/10251/81010

This paper must be cited as:

Broatch Jacobi, JA.; Margot, X.; Novella Rosa, R.; Gómez-Soriano, J. (2016). Combustion noise analysis of partially premixed combustion concept using gasoline fuel in a 2-stroke engine. Energy. 107:612-624. doi:10.1016/j.energy.2016.04.045.

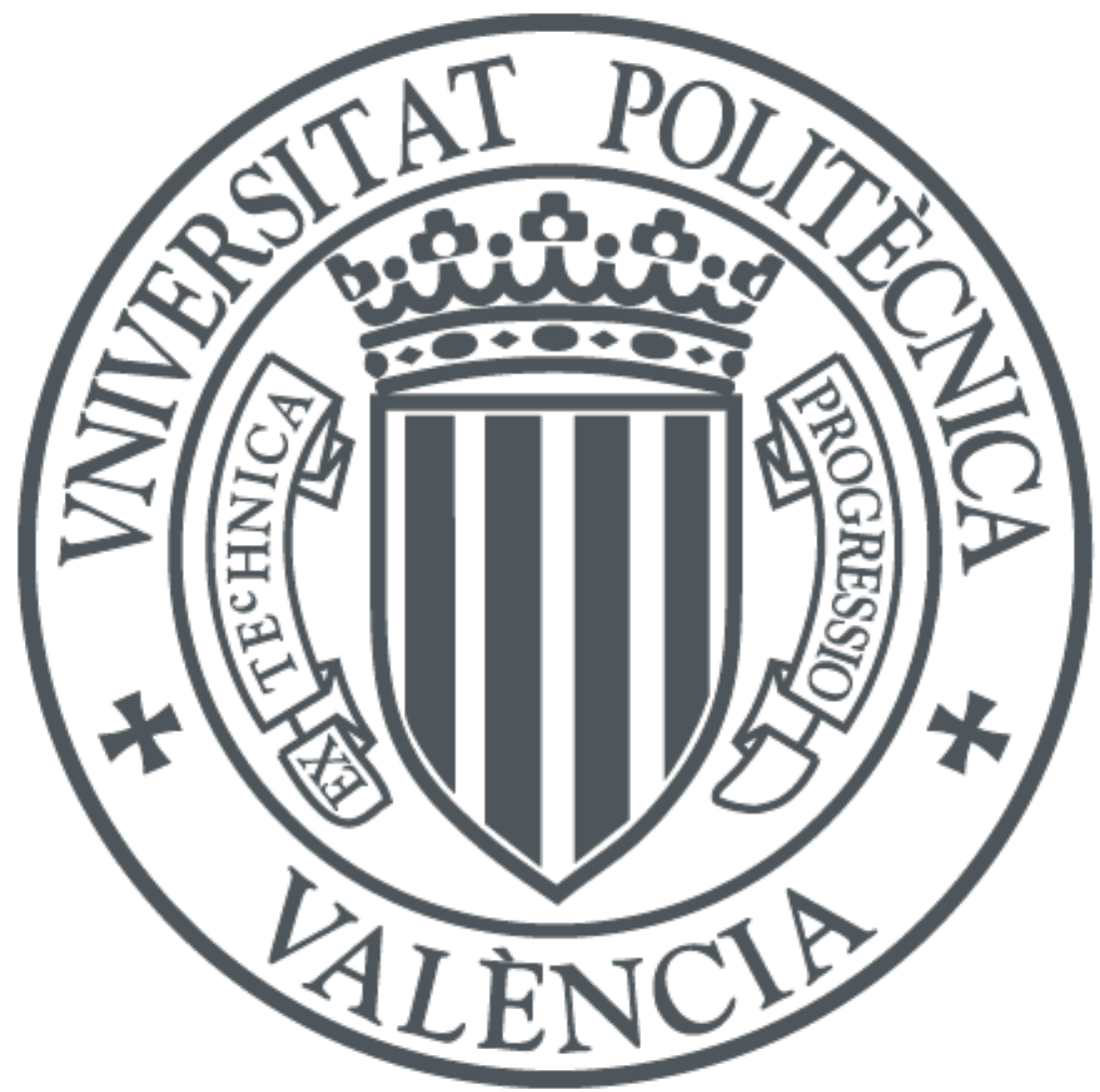

The final publication is available at

http://dx.doi.org/10.1016/j.energy.2016.04.045

Copyright Elsevier

Additional Information 


\title{
Combustion noise analysis of partially premixed combustion concept using gasoline fuel in a 2-stroke HSDI engine
}

\author{
A. Broatch, X. Margot, R. Novella*, J. Gomez-Soriano \\ CMT - Motores Térmicos, Universitat Politècnica de València \\ Camino de Vera, 46022 Valencia
}

\begin{abstract}
In the last decade, different advanced combustion concepts based on generating totally or partially premixed conditions have been investigated in CI engines with the aim of achieving lower NOx and soot emissions. Most of the drawbacks inherent to this type of combustions, such as the combustion phasing control or combustion stability, can be mitigated by combining the PPC concept fueled by gasoline and a small 2-stroke HSDI engine. However, combustion noise issue remains unsolved while it is a critical aspect due to its strong influence in the customer purchasing decision and compliance of more stringent regulations. In this work, an analysis of the combustion noise generated by PPC combustion concept is performed in order to identify the most influential parameters and to define key paths for controlling the noise level. In addition, 3D CFD simulations have been performed to further understand the combustion noise generation mechanisms. Results evidence how the strong impact of the maximum pressure time-derivative achieved during combustion process renders all other sources of noise generation irrelevant. The trade-off between combustion noise and combustion efficiency of this PPC concept has been confirmed, while the intrinsic relation between such parameters and the engine efficiency has been also evaluated.
\end{abstract}

Keywords: Gasoline PPC, Combustion noise, 2-stroke CI engine, CFD model validation

\section{Introduction}

In the past two decades, an increasing concern about environmental contamination and its effects on the human life frame have led to more stringent exhaust emission regulations in the transport sector, especially in the passenger cars segment. During this period, direct injection (DI) compression ignition (CI) diesel engines have become the leading power plant of lightduty vehicles in Europe, due to their higher efficiency and technological margin of improvement, in comparison with spark ignition (SI) engines. Until recent years, diesel engine developments such as fuel injection system, EGR, turbo-charging and after-treatment, have allowed the fulfillment of the emissions standards, particularly in terms of nitrous oxides (NOx) and particulate matter (PM), while improving engine performance and driveability. However, extremely restrictive regulations for exhaust emissions as well as for noise emissions [1,2] expected for the future demand further advances.

In most diesel engines, these emissions can be mitigated by a combination of close management of the combustion with the newest aftertreatment solutions. While soot control is achieved using Diesel Particulate Filters (DPF) along the exhaust system, other after-treatment solutions such as Lean Nox Trap (LNT) or

\footnotetext{
${ }^{*}$ Corresponding author. Tel.: +34 9638776 55; fax: +34 963877659 Email addresses: abroatch@mot.upv.es (A. Broatch), xmargot@mot.upv.es (X. Margot), rinoro@mot.upv.es (R. Novella), jogoso1@mot.upv.es (J. Gomez-Soriano)
}

Selective Catalytic Reduction (SCR) allow reducing NOx emissions. However, these technologies require recurrent regeneration cycles and the addition of a reducing agent, which worsens fuel consumption. Recent research works are focused on avoiding the formation of these pollutants during the combustion process. For example, water injection methods -direct water injection, fumigation or emulsion- have demonstrated their capability to reduce NOx formation during the combustion process $[3,4]$. On the other hand, condensed water into the cylinder deteriorates the oil lubrication properties, thus compromising the engine durability. Some authors overcome this drawback by injecting water in steam phase. The steam injection method reduces NOx levels and increases the engine efficiency $[5,6,7,8]$. However, the water injection methods requiere very complex injection systems. The Miller cycle has been proposed as another solution to comply with NOx regulations. This method is based on a decrease of the combustion temperatures by reducing the effective compression ratio through the air management settings $[9,10]$. The main disadvantage of this method is that it implies a worsening of engine performance. Recent studies suggest to combine the Miller cycle with turbocharging in order to improve the engine performance and control NOx emissions [11].

Thus, in order to reduce after-treatment costs, the injection system complexity and fuel consumption, various advanced low temperature combustion (LTC) concepts have been thoroughly investigated for their benefits in achieving simultaneously reductions in NOx and soot emissions during the combustion pro- 
cess. In this type of combustions, such as HCCI and PCCI, diesel fuel is burned in highly premixed conditions to prevent the soot formation while the local temperatures are kept as low as possible to inhibit NOx production [12, 13, 14, 15, 16]. Among these solutions, the Partially Premixed Combustion (PPC) strategy allows to operate between completely premixed and wholly diffusive conditions, whereby low emissions may be attained while retaining the combustion timing control with the injection event. Further investigations have confirmed the ability of the PPC concept fueled by low reacting fuels, such as gasoline or ethanol, to achieve very low emissions of both NOx and soot particulates while maintaining the indicated efficiency [17, 18, 19].

Despite the attractive benefits of the gasoline PPC concept, important technological drawbacks inherent to the combustion process must be solved; among others, the accurate control of the combustion phasing and the combustion noise [20]. The main issue lies probably in the combustion control, as the injection event alone does not ensure combustion. This fact added to the narrow operation margin defined by the combustion limits, i.e. high combustion (knock) and unstable combustion (misfire), lead to a reduced load operation range. Nevertheless, in recent research work [21, 22, 23], it appears that an innovative 2-stroke HSDI CI engine could represent a promising solution to control the combustion timing and to extend the load range. Indeed, as proven by these investigations, the ability of this engine to control the cylinder conditions through the air management settings allows to fix the local fuel concentration at the start of the combustion. This means that it is possible to keep the local equivalence ratios in the most reactive band (between 0.4 and 2.5), so as to avoid the production of soot precursors while ensuring combustion efficiency and stability. However, by delaying the combustion start, the increased $\mathrm{HC}$ and $\mathrm{CO}$ amounts in the exhaust cause important efficiency losses of the combustion process and this evidences a new trade-off between combustion efficiency and NOx-soot emissions [24].

Engine manufacturers are very concerned by the noise increase obtained with these new combustion concepts, because in most cases the engine noise levels are too high to comply with future and even current legislations. And, moreover, because the engine noise perception has a strong influence on the customer purchasing decision. Current research efforts are therefore focused on the reduction of the premixed combustion overall noise levels $[25,26]$ and on the improvement of the sound quality [27, 28].

The combustion process contributes as a noise source through the interaction of the pressure and mechanical forces. Pressure forces act directly on the surface of the combustion chamber and induce the engine block vibrations, which are responsible for noise emission. Mechanical forces, which are due to the pressure forces transmitted by moving elements in the cylinder, piston slap, clearances, friction and deformation [29, 30, 31], also contribute as an additional vibration source. The forces described above depend strongly on the sudden pressure rise due to the auto-ignition, which is mainly characterized by the fuelburning velocity, and hence by the rate of heat release (RoHR). Besides, the pressure rise also produces high frequency oscil- lations of the cylinder gas, which are associated to an unsteady process known as combustion chamber resonance [32, 33]. This phenomenon needs to be taken into account because of the high levels of energy contained in the oscillations and its characteristic excitation frequency range, which is in the highly sensitive human perception range. The combustion chamber resonances are mostly influenced by the gas temperature and the bowl geometry.

Regarding noise radiation through the engine structure, previous investigations have shown different propagation patterns of the acoustic energy [34, 35, 36]. This acoustic response is highly non-linear and time dependent and it is extremely influenced by the engine block design. Traditionally, a classical approach [37] is used to link the in-cylinder pressure level with the radiated noise level. This procedure assumes a linear behavior between noise source and free-field propagation in order to obtain the engine noise radiation. Several combustion noise meters are defined taking into account this method to estimate the radiated noise level from the in-cylinder pressure signal. Even though this simplification does not allow an accurate prediction of the radiated noise level, it provides a useful tool in qualitative analysis.

The excitation source (pressure and mechanical forces) of combustion noise is characterized by the in-cylinder pressure, while the radiated noise is attributed to the engine block vibration and later propagation. Hence, there are two different strategies to reduce combustion noise levels [38]. The first consists in optimizing both hardware and settings to act directly on the noise source (active solutions), and the second is based on the engine encapsulation (passive solutions).

The main objective of this research is to examine the variation of the combustion noise by modifying the timing of the injection event in a 2-stroke HSDI CI engine operating with the PPC concept using RON95 gasoline. In order to achieve this target, features such as combustion noise generation/propagation mechanisms and influencing parameters, should be analyzed.

In the next two sections, a description of the experimental set up and numerical tools is presented. The methodology followed in this study is described in Section 4. Then, an extended validation procedure of the numerical results is detailed in Section 5, while both experimental and CFD results for combustion noise are presented and thoroughly discussed in Section 6. Finally, the conclusions obtained from this investigation are summarized in Section 7.

\section{Experimental setup}

\subsection{Engine architecture}

The experimental activities have been carried out in a singlecylinder research version of an innovative engine concept characterized by a 2 -stroke HSDI CI engine with poppet valves scavenge loop. As a reference, the main specifications of this engine are included in Table 1.

A particular design of the cylinder head displayed in Figure 1 was adopted to optimize the scavenging of burnt gases while keeping short-circuit losses as small as possible during the 2stroke cycle. The cylinder head geometry exhibits a staged roof 
Table 1: Engine specifications

\begin{tabular}{ll}
\hline Engine type & 2-stroke HSDI Compresion Ingition \\
\hline Number of cylinders [-] & 1 \\
Displacement $\left[\mathrm{cm}^{3}\right]$ & 365 \\
Bore - Stroke $[\mathrm{m}]$ & $0.076-0.0805$ \\
Connecting rod length $[\mathrm{m}]$ & 0.143 \\
Compression ratio $($ geometric $)$ & $17.8: 1$ \\
Compression ratio (effective) & From $13.0: 1$ to $8.8: 1$ \\
Number of valves [-] & 2 intake and 2 exhaust \\
Type of scavenge & Poppet valves with scavenge loop \\
Valvetrain & Double overhead camshaft with VVT \\
Nominal intake valve timing $[\mathrm{cad}$ aTDC $]$ & IVO $=161.9$ - IVC $=251.6$ \\
Nominal exhust valve timing $[\mathrm{cad}$ aTDC $]$ & EVO $=122.6$ - EVC $=226.9$ \\
\hline
\end{tabular}

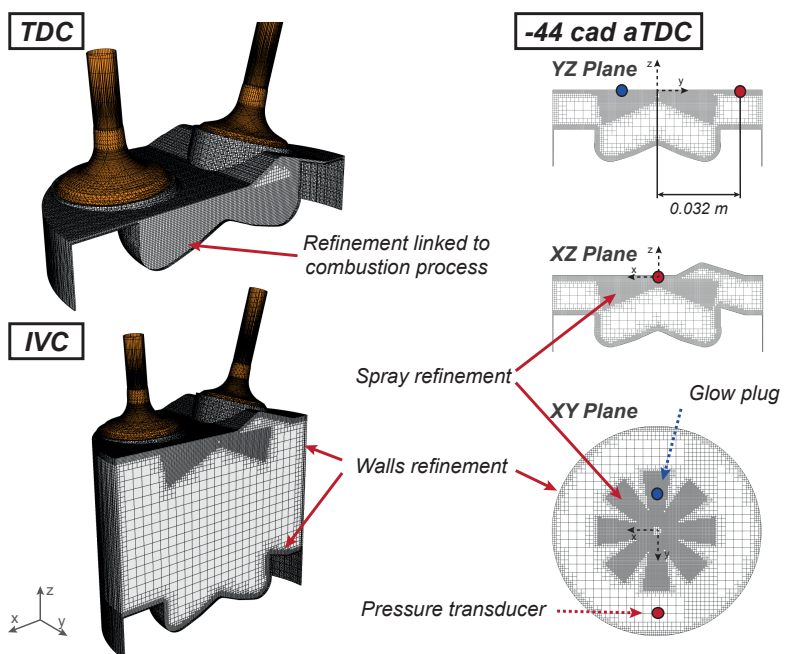

Figure 1: Computational domain and mesh characterization of the engine architecture

for baffling the air flow between intake and exhaust valves, directing the air to the cylinder wall toward the bottom of it. This geometry represents the best compromise between scavenging efficiency, acceptable permeability, and favorable combustion chamber design [39].

The timing control of the four poppet valves actuated by double-overhead camshafts relies on a hydraulic cam-driven Variable Valve Timing (VVT) system, which allows delaying both intake and exhaust valve timings up to +30 degrees from the base cam phasing. This system is well adapted for modifying the air management characteristics, due to its flexibility to adjust the overlap period between intake and exhaust, but also the effective compression and effective expansion ratios.

The engine is equipped with a common rail prototype fuel injection system, which grants a maximum rail pressure of 1800 bar. For tests performed with diesel fuel an optimized 8 hole injector with nozzle diameters of $90 \mu \mathrm{m}$ and an included spray angle of $155^{\circ}$ was used; for the PPC concept tests with gasoline a different nozzle configuration was chosen with also 8 holes of the same diameter, but with an included angle of $148^{\circ}$. Table 2 includes the injection system configuration and main fuel properties for each combustion concept. The piston bowl geometry employed for both combustion concepts tests was of a conventional design, optimized for operating with the Conventional
Diesel Combustion (CDC) concept, and provided a geometric compression ratio of 17.6.

Mass flow rate and spray momentum flux were measured in dedicated test rigs $[40,41]$ for the previously described injection configurations in similar test conditions, in order to provide the most realistic injection characterization for the CFD calculations.

\subsection{Test cell characteristics}

The research engine unit was installed in a fully instrumented test cell, equipped with all the auxiliary devices required for the engine operation, such as an external compressor for supplying compressed air and simulate the boost conditions, and independent water and oil cooling circuits. The exhaust back-pressure produced by the turbine is reproduced by a throttle valve located downstream of the exhaust settling chamber. Besides, the cell installation also includes an additional low pressure EGR system to provide diverse amounts of cooled exhaust gas even at very high intake boost pressures.

Measurements of chemical exhaust gas components such a $\mathrm{O}_{2}, \mathrm{CO}, \mathrm{CO}_{2}, \mathrm{HC}, \mathrm{NO}_{x}, \mathrm{~N}_{2} \mathrm{O}$, and EGR rate are obtained close to the exhaust settling chamber with an Horiba MEXA7100 DEGR gas analyzer. The filter smoke number (FSN) is measured using an AVL 415 Smokemeter and soot emissions are later estimated from the correlation

$$
\operatorname{Soot}[\mathrm{mg} / \mathrm{s}]=\frac{1}{0.405} \cdot \alpha \cdot F S N \cdot e^{\beta \cdot F S N} \cdot \dot{q}_{\text {exh }}\left[\mathrm{m}^{3} / \mathrm{s}\right]
$$

where $\dot{q}_{\text {exh }}$ is the volumetric flow rate at the exhaust and the value of the constants are $\alpha=5.32$ and $\beta=0.31$ [42]. The correlation is valid for FSN values up to 8. In addition, the trapping ratio, defined as the mass of delivered charge trapped into the cylinder divided by the mass of delivered charge supplied, is estimated by means of a $\mathrm{CH}_{4}$ tracer method for each operating point. The internal gas recirculation ratio, which is defined as the concentration of retained gases from the previous combustion cycle in the total trapped mass in the cylinder, is approximated by simplified thermodynamic calculations. The combustion efficiency is determined from both measured $\mathrm{CO}$ and unburned HC levels as [43]

$$
\eta_{\text {comb }}=\left(1-\frac{m_{H C}}{m_{\text {fuel }}}-\frac{m_{C O}}{4 \cdot m_{f u e l}}\right) \cdot 100
$$


Table 2: Injection system characterization and main fuel properties

\begin{tabular}{lll}
\hline Performed tests & CDC tests & PPC tests \\
\hline Injection system [-] & Delphy DFI1.5 Common rail HSDI system \\
Injector nozzle design [o - holes $-\mu \mathrm{m}]$ & $155-8-90$ & $148-8-90$ \\
Maximum allowed injection pressure $[$ bar $]$ & 1800 & 1100 \\
Test fuel [-] & Diesel fuel & Unleaded gasoline \\
Cetane number [-] & 46.6 & - \\
Research octane number [-] & - & 94.6 \\
LHV $[\mathrm{MJ} / \mathrm{kg}]$ & 42.124 & 42.820 \\
\hline
\end{tabular}

where $m_{H C}$ represents the mass of unburned $\mathrm{HC}$ emissions, $m_{C O}$ is the mass of CO and $m_{f u e l}$ is the injected mass fuel. And the thermodynamic efficiency is defined as

$$
\eta_{\text {thermo }}=\frac{\eta_{\text {indicated }}}{\eta_{\text {comb }}}
$$

While the in-cylinder pressure is measured with a Kistler 6061B pressure transducer placed between exhaust and intake valves at the opposite of the glow plug location (as can be seen in Figure 1), a different piezoresistive pressure sensor is used to reference this sensor signal. Cylinder pressure and other relevant high frequency signals are sampled using a dedicated acquisition system and recorded during 100 engine cycles for each operation condition. The latter signals are also registered with a sample frequency of $45 \mathrm{kHz}$, in order to obtain a free-aliasing bandwidth similar to the human domain of hearing $-20 \mathrm{~Hz}$ to $20 \mathrm{kHz}$ - according to Nyquist criterion [44].

The most relevant combustion parameters, such as indicated mean effective pressure (IMEP), combustion phasing angles, maximum in-cylinder pressure, maximum pressure time-derivative, thermal efficiency, combustion efficiency, and RoHR are calculated from the in-cylinder pressure signal by means of inhouse combustion software [45, 46, 47]. This code assumes uniform pressure and temperature throughout the whole combustion chamber volume to solve the energy equation, providing the instantaneous mean temperature and the heat release. Additionally, the code offers the initial thermodynamic conditions and wall temperatures [48] required for the boundary conditions of the CFD model.

\section{Numerical model setup}

The commercial CFD platform CONVERGE based on the finite volume method was used to analyze the in-cylinder pressure variations and their contribution to the radiated noise. The structured mesh of the full three-dimensional combustion chamber computational domain is formed by hexahedrons of base cell size $3 \mathrm{~mm}$. In order to achieve a higher level of accuracy for simulating wall reflection phenomena, three levels of grid refinement were added to the original mesh size in the areas of the domain walls and the spray zones (view Figure 1). In addition, two grid refinement levels were activated in the current domain at combustion start in order to reproduce the pressure waves interaction. Additionally, the code used an adaptive mesh refinement algorithm (AMR) to increase the spatial resolution in zones where flow velocity and temperature variations were significant. The number of cells depended on the simula- tion parameters and varied between a million cells at the end of the calculation and half million cells at TDC.

The injection process was simulated by the standard Discrete Droplet Model using iso-octane as a surrogate to predict the physical properties of gasoline fuel. The injection rate was defined by the experimental data obtained with the injector characterization process described in Section 2.1, which is based on mass flow rate and spray momentum flux measurements. The KH-RT model was used to predict the spray atomization and break-up. Turbulent flow properties were obtained by means of the RNG $k-\epsilon$ model [49] with estimated wall heat fluxes [50].

The code makes a direct integration to approach the detailed chemistry of the domain with the SAGE solver. A chemical mechanism corresponding to a Primary Reference Fuel (PRF) combining n-heptane (5\%) and iso-octane (95\%) was selected as a suitable surrogate for the ignition characteristic of the RON95 gasoline actually used in the experimental tests.

The simulations included the process between intake valve closing (IVC) and exhaust valve opening (EVO). A dynamic time step strategy based on two different Courant number definitions -displayed in Equations (4) and (5) - was adopted to capture the high-frequency pressure variations and to reduce the computational time.

$$
\begin{aligned}
& C_{u}=u \frac{\Delta t}{\Delta x} \\
& C_{c}=c \frac{\Delta t}{\Delta x}
\end{aligned}
$$

where $u$ is the flow velocity, $c$ is the speed of sound, $\Delta x$ is the cell size and $\Delta t$ is the time step. The time step was calculated by keeping the Courant number close to one and considering the cell size and a characteristic velocity. The flow velocity was taken as characteristic velocity during the compression and injection phases, whereas the speed of sound was considered in the combustion phase in order to ensure an accurate prediction of the pressure waves propagation.

In this case, all computed variables were recorded at a sampling frequency of $50 \mathrm{kHz}$ to provide enough free-aliasing bandwidth to cover the human hearing range. Moreover, for the simulations a monitor was placed at the same location as the experimental transducer, in order to take into account the strong influence of the pressure transducer location in the pressure measurements, especially in the high frequency range [51].

All computations were performed using an internal cluster formed by 4 Fujitsu RX500 servers and 72 Fujitsu BX920 blades with 1280 parallel threads. The computational time was 
about 60 hours for each engine operation condition, when the process was distributed on 32 parallel threads.

\section{Methodology}

For this investigation, an operating condition defined by medium speed (1500 rpm) and medium-high load (10.4 bar IMEP) was selected. The noise generation mechanism of the engine was evaluated for two combustion concepts, optimized CDC and PPC fueled with gasoline. The former was used as the reference case to establish solid comparisons with the newly advanced combustion concept and to validate the CFD model results. Furthermore, the provided pollutant emissions, noise and performance characteristics in CDC are set as targets. The main characteristics of the operating points are included in Table 3.

According to previous investigations [52, 53], the second injection timing -defined by the Start of Energizing of the injector ( $\mathrm{SoE})$ - is one of the most influential parameters for noise generation, due to its impact on the RoHR and hence on the maximum pressure time-derivative. For this reason an experimental sweep of the second injection timing was performed for the gasoline PPC concept tests as shown in Table 3.

An appropriate data processing methodology was defined in this study. First, all parameters used in this work were calculated for each cycle and averaged a posteriori in order to retain the spectrum information and the contribution to the estimation of noise. Next a statistical analysis based on the root mean square minimization (RMS) was carried out to select the most representative cycle among those recorded. This procedure aims at selecting the cycle which presents less deviation from the average considering the two most influential parameters for combustion noise: maximum pressure time-derivative and resonance energy. These parameters were selected taking into account the information reported in the literature [26, 27]. In this way the selected cycle should be representative of the noise generated during the engine test and can be used to compare different operating conditions .

Finally, further studies have been carried out to analyze the spectrum trace and radiated noise trends. Numerical simulations were also performed in order to extend the narrow operating range between knock conditions and unstable combustion that limited the experimental suitable testing range. It was thus possible to explore a wider range of results in terms of combustion noise and engine efficiency, and define future key paths for further optimization of the gasoline PPC concept.

\section{Validation}

\subsection{Time-domain parameters}

The CFD model described in Section 3 was validated taking into account the experimental data from tests 01 and 02 included in Table 3. These tests correspond to an optimized case operating with the CDC concept and to the baseline case operating with the gasoline PPC concept respectively.

The usual validation method is based on reproducing the incylinder pressure profile averaged from a given number of recorded cycles. However, this averaging procedure removes the

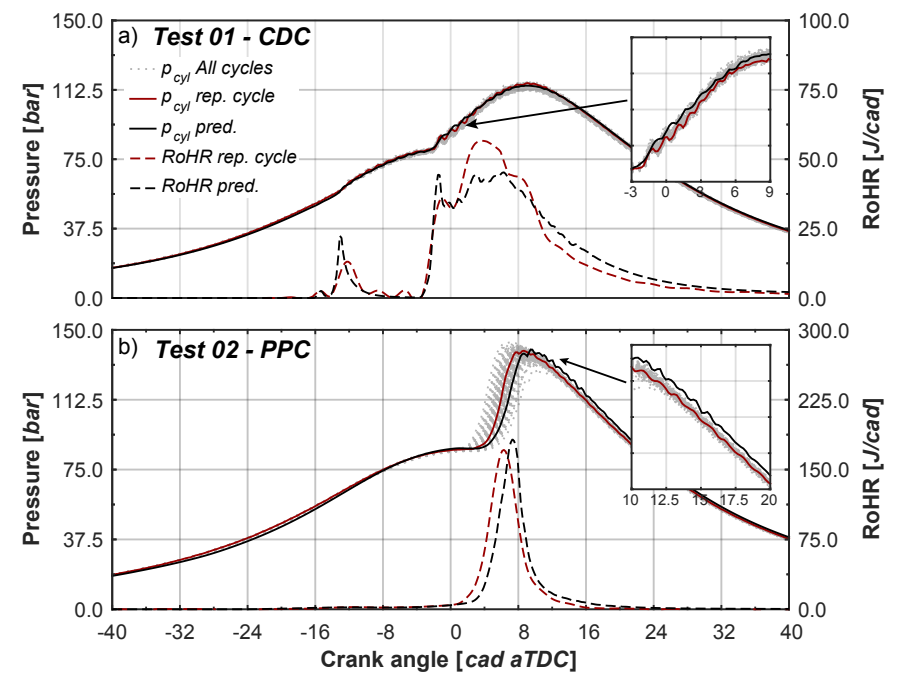

Figure 2: Measured and CFD calculated in-cylinder pressure and RoHR traces. a) CDC concept (test 01), b) Gasoline PPC concept (test 02)

high frequency oscillations -like a low-pass filter- and, in consequence, high frequency components of the noise source cannot be assessed. For this reason the most representative cycle obtained by means of the statistical study described in Section 4 was used as a reference for validation.

As previously described, the in-cylinder pressure was instantaneously recorded by means of a piezoelectric sensor. In the CFD calculations the temporal evolution of the in-cylinder pressure was recorded with a monitor located at the same point as the experimental transducer. The experimental and CFD pressure profiles and the corresponding RoHR traces of test cases 01 and 02 are compared in Figure 2. In order to evaluate the suitability of the CFD model to predict combustion, engine performance and exhaust emissions parameters, a comparison between measured and CFD calculated parameters has been included in Table 4. The relative error for an arbitrary variable $(\phi)$ is defined as

$$
\epsilon_{r}[\%]=\frac{\left|\phi_{C F D}-\phi_{\exp }\right|}{\phi_{\exp }} \cdot 100
$$

In addition, the relative error between measured and CFD calculated pressure traces has been estimated as a function of crank angle $\left(\epsilon_{r}(\alpha)\right)$ in order to obtain the maximum relative error during the cycle $\left(\epsilon_{r}^{\max }\right)$.

The examination of the CDC concept results yields that the maximum relative error between the measured pressure trace and the CFD calculated one is $5.64 \%$. The pressure evolution is therefore well reproduced by the state of the art CFD simulations. However, RoHR traces show significant differences especially during the mixing-controlled combustion phase, where the calculation overestimates the pressure at EVO. Also the estimated unburned HC levels present an important deviation from experimental results $\left(\epsilon_{r}=96.67 \%\right)$ due to limitations of the numerical model for calculating the liquid-film evaporation.

For the gasoline PPC concept, the model also correctly pre- 
Table 3: Main engine settings for all operating points evaluated in this investigation.

\begin{tabular}{|c|c|c|c|c|c|c|c|c|c|c|c|c|c|}
\hline $\begin{array}{l}\text { Test } \\
{[-]}\end{array}$ & $\begin{array}{l}\text { Concept } \\
{[-]}\end{array}$ & $\begin{array}{l}\text { EGR } \\
{[\%]}\end{array}$ & $\begin{array}{l}p_{\text {int }} \\
{[\text { bar }]}\end{array}$ & $\begin{array}{l}\text { Overlap } \\
{[\mathrm{cad}]}\end{array}$ & $\begin{array}{l}\text { VVT (int, exh) } \\
{[\mathrm{cad}]}\end{array}$ & $\begin{array}{l}\text { Effective CR } \\
{[-]}\end{array}$ & $\begin{array}{l}p_{\text {rail }} \\
{[\text { bar }]}\end{array}$ & $\begin{array}{l}\text { SoE1 } \\
\text { [cad aTDC] }\end{array}$ & $\begin{array}{l}\text { SoE2 } \\
{[\text { cad aTDC] }}\end{array}$ & $\begin{array}{l}\text { SoE3 } \\
{[\text { cad aTDC] }}\end{array}$ & $\begin{array}{l}\text { Injected fuel } \\
{[\mathrm{mg} / \mathrm{str}]}\end{array}$ & $\begin{array}{l}\text { Fuel ratio } \\
{[-]}\end{array}$ & $\begin{array}{l}\text { Air/Fuel ratio } \\
{[-]}\end{array}$ \\
\hline $01^{*}$ & $\mathrm{CDC}$ & 11.88 & 2.50 & 73.4 & $(10,20)$ & 11.47 & 1000 & -20.00 & -7.00 & - & 19.60 & $11 / 89$ & 25.07 \\
\hline $02 *$ & & 43.53 & & & & & & & -40.00 & & & & 21.96 \\
\hline 03 & & 43.66 & & & & & & & -42.00 & & & & 22.12 \\
\hline 04 & Gasoline PPC & 43.58 & 2.75 & 78.4 & $(5,20)$ & 12.15 & 850 & -60.00 & -38.00 & -2.00 & 19.10 & $20 / 64 / 16$ & 22.19 \\
\hline 05 & & 43.50 & & & & & & & -36.00 & & & & 22.46 \\
\hline $06^{*}$ & & 43.56 & & & & & & & -34.00 & & & & 22.42 \\
\hline $\begin{array}{l}07 * * \\
08 * *\end{array}$ & Gasoline PPC & 43.53 & 2.75 & 78.4 & $(5,20)$ & 12.15 & 850 & -60.00 & $\begin{array}{l}-46.00 \\
-52.00\end{array}$ & -2.00 & 19.10 & $20 / 64 / 16$ & $\begin{array}{l}21.96 \\
21.96\end{array}$ \\
\hline
\end{tabular}

Table 4: Comparison between measured and CFD calculated parameters in both validation cases, CDC concept (test 01) and gasoline PPC concept (test 02)

\begin{tabular}{lllll}
\hline & \multicolumn{2}{c}{ Test 01 - CDC } & \multicolumn{2}{c}{ Test 02 - PPC } \\
& CFD & Experiment & CFD & Experiment \\
\hline$p_{\max }[$ bar $]$ & 114.73 & 114.70 & 138.48 & 138.30 \\
$(d p / d \alpha)_{\max }[$ bar $/ \mathrm{cad}]$ & 5.90 & 4.50 & 17.79 & 17.78 \\
CA50 [cad aTDC $]$ & 7.82 & 6.10 & 7.40 & 6.30 \\
$\eta_{\text {indicated }}[\%]$ & 45.06 & 45.75 & 46.92 & 46.76 \\
NOx $[\mathrm{mg} / \mathrm{s}]$ & 5.56 & 5.90 & 0.61 & 0.60 \\
Soot $[\mathrm{mg} / \mathrm{s}]$ & 0.087 & 0.067 & 0.007 & 0.035 \\
HC $[\mathrm{mg} / \mathrm{s}]$ & 0.01 & 0.30 & 12.03 & 9.14 \\
CO $[\mathrm{mg} / \mathrm{s}]$ & 4.75 & 3.75 & 18.01 & 16.51 \\
\hline
\end{tabular}

dicts the pressure trace $\left(\epsilon_{r}^{\max }=6.76 \%\right)$. In addition, in this case the simulated RoHR only presents a slight delay that causes a slight over-prediction of the maximum pressure. However, the rest of the characteristic parameters chosen as representative of the thermodynamic conditions present good agreement as shown in Table 4. This means that the CFD model may be considered sufficiently accurate to carry out further detailed analysis on noise.

\subsection{Frequency-domain parameters}

Although the model performance is suitable to predict classical parameters considered in the literature $[54,55]$, the simulation of the complex phenomena present in the sound generation due to the combustion process demands further validation to ensure that the numerical model results are representative of combustion radiated noise. So in order to check the ability of the model to predict the pressure variations as noise source, a new validation methodology based on a frequency-domain analysis is proposed.

The first step consists in characterizing the resonance phenomenon with a numerical value, which represents the amplitude of the high frequency oscillations in the pressure trace $\left(E_{\text {res }}\right)$ [56]. For this the resonant pressure fluctuations, or 'resonance signal', are separated from the whole pressure signal. These are clearly identifiable by the presence of high amplitude peaks in the pressure spectrum at high frequencies. Then, the resonance signal may be identified by high-pass filtering of the pressure signal. The filter cut-off frequency is fixed by an empirical function which depends on the engine speed as defined in [57]

$$
f_{\text {cut }}=2.364 \cdot n-2.91 \cdot 10^{-4} \cdot n^{2}
$$

As is usual in the field of signal treatment, $E_{r e s}$ is defined as the energy emitted from one Ohm resistive circuit considering the pressure as an electric signal

$$
E_{r e s}=\int_{I V C}^{E V O} p(t)_{r e s}^{2} d t
$$

where $E_{\text {res }}$ is the resonance energy of the signal, defined from the resonance pressure signal $\left(p_{\text {res }}\right)$ and evaluated between IVC and EVO.

Moreover, in order to evaluate the source of combustion noise at each operation condition the overall pressure level, termed 'cylinder pressure level' (CPL), is estimated using the following expression:

$$
C P L(d B)=10 \cdot \log \frac{P_{N}^{2}}{p_{0}^{2}}
$$

where $p_{0}=20 \mu P a$ and

$$
P_{N}=\frac{1}{N} \cdot \sum_{f=f_{1}}^{f_{N}} P(f)
$$

where $\mathrm{N}$ is the number of harmonics between $f_{1}$ and $f_{N}$, while $P(f)$ represents the Fast Fourier Transform of the pressure signal $(p(t))$. Similarly, the overall noise level of the radiated engine noise, from now on termed 'overall noise' (ON), can be determined by applying Equation (9) to the spectrum of the engine noise. This spectrum is estimated by subtracting the block attenuation curve from the in-cylinder pressure spectrum. As reported in previous studies [26], the block attenuation is usually obtained by performing a high number of costly tests, which can be avoided by using standard curve definition [37]. So the combustion noise source is quantified by the CPL -assessed 

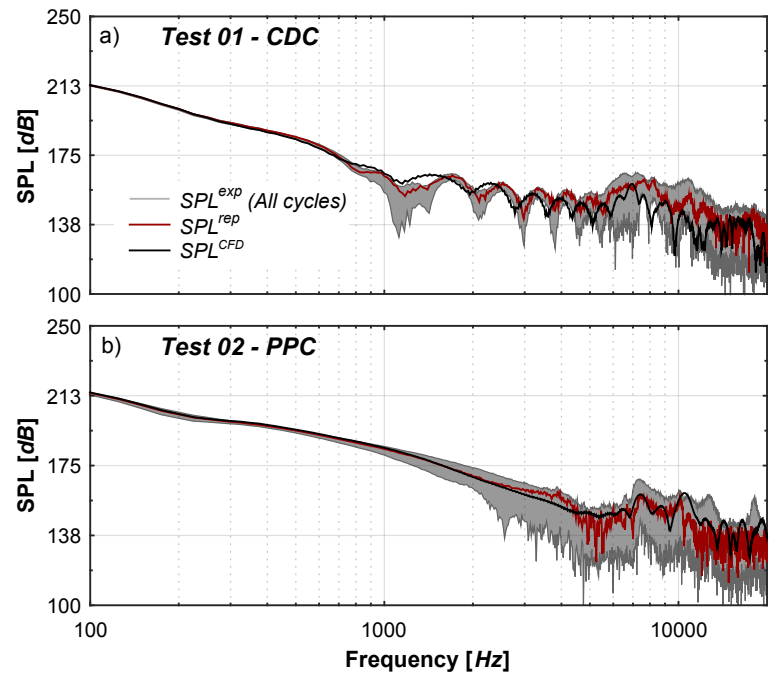

Figure 3: Measured and CFD calculated spectra traces. a) CDC concept (test 01), b) Gasoline PPC concept (test 02)

from the spectra of in-cylinder pressure signal- whereas the engine noise, represented by the radiated engine noise, is characterized by the ON level.

In Figure 3 the in-cylinder pressure spectra of all measured cycles are presented together with the spectrum calculated by CFD. Focusing on the CDC results, the amplitude level is well reproduced up to $4 \mathrm{kHz}$. For higher frequencies there is higher dispersion between measured and CFD calculated results. A similar behavior is observed in the case of the gasoline PPC concept; while medium-low frequencies are well reproduced, the high ones present a larger deviation. However, neither CPL nor ON predictions are affected by this, as shown in Table 5 by the very small relative errors (less than $0.5 \%$ ) between measured and calculated levels. On the contrary, the differences between measured and CFD calculated $E_{\text {res }}$ results are relatively large, especially in the CDC case, and further analysis is needed in order to reproduce the resonance phenomena accurately.

Despite these discrepancies in the spectra, the CFD results exhibit reasonable consistency with the experimental measurements. Hence, the model demonstrates enough ability to reproduce and characterize the combustion noise source.

\subsection{Experimental results validation}

As mentioned previously, the sudden rise of pressure due to the combustion process produces high frequency oscillations of the cylinder gas with particular patterns commonly known as higher order modes $[32,58]$. These modes present different oscillation amplitudes around zero-amplitude or node zones. Previous studies $[51,59,60]$ have evidenced the strong influence of the pressure transducer location on the recorded signals, especially in the high frequency range, when evaluating the effects of these phenomena inside DI combustion chambers. Figures 4 and 5 display the results of a preliminary CFD study performed to explain the influence of pressure variation in the combustion chamber on engine radiated noise. The $\mathrm{ON}$ has been calculated
Table 6: ON level variations due to resonance inside the combustion chamber

\begin{tabular}{llll}
\hline $\begin{array}{l}\text { Test } \\
{[-]}\end{array}$ & $\begin{array}{l}O N_{\text {trans }} \\
{[d B]}\end{array}$ & $\begin{array}{l}O N_{\max } \\
{[d B]}\end{array}$ & $\begin{array}{l}\epsilon_{r} \\
{[\%]}\end{array}$ \\
\hline 01 & 87.36 & 91.96 & 4.99 \\
02 & 99.71 & 101.11 & 1.38 \\
06 & 104.31 & 106.09 & 1.68 \\
07 & 97.50 & 98.57 & 1.09 \\
08 & 87.72 & 88.27 & 0.63 \\
\hline
\end{tabular}

in all active cells at TDC with the procedure described in the previous section and represented in the combustion chamber using contour plots. Two main conclusions can be extracted from this study: The ON contours evidence on the one hand that there are significant overall noise level differences inside the combustion chamber in both CDC and PPC concepts; and on the other hand, that the effect of the resonance is less relevant in the gasoline PPC concept. Indeed, the variation range in the gasoline PPC concept is approximately $2 \mathrm{~dB}$ whereas it is almost $7 \mathrm{~dB}$ in the $\mathrm{CDC}$ concept.

In addition, it is evident that the pressure transducer should be placed near the cylinder walls where the ON levels are higher due to the resonance. Unfortunately, the pressure transducer cannot be placed at the optimum location because of all the components of the cylinder head (injector, glow plug and valves) Hence, in order to ensure that the resonance measurements in the combustion chamber are reliable, it is necessary to establish an acceptance zone for the transducer location, defined by a minimum threshold. The averaged $\mathrm{ON}$ from all active cells at TDC is fixed as the minimum acceptable value. Figures 4 and 5 show that the pressure transducer is located within the acceptance zone in test 02 operating with the gasoline PPC concept, while it is outside this zone in test 01 operating with the CDC concept.

Table 6 compares the maximum ON level inside the combustion chamber, as calculated by CFD, with the experimentally estimated $\mathrm{ON}$, in order to quantify the error in the measurements due to the experimental transducer location. As expected, the relative errors obtained in the gasoline PPC concept cases are lower than the ones in the CDC concept cases. While the gasoline PPC concept offers a high level of confidence with a maximum relative error of $1.68 \%$, the CDC concept presents a lower degree of reliance with a maximum relative error close to $5 \%$. These results show that the in-cylinder pressure signals measured in the gasoline PPC concept tests represent adequately the combustion noise source, whereas the measurements in the CDC tests can be used only as reference levels in terms of combustion noise and engine efficiency.

\section{Results and discussion}

\subsection{Analysis of the gasoline PPC concept}

A preliminary analysis was performed with the experimental results obtained with the SoE sweep of the second injection detailed in Table 3, in order to describe the gasoline PPC concept in terms of efficiency, noise and exhaust emissions. Figure 
Table 5: Comparison between measured and CFD calculated frequency parameters in both validation cases, CDC concept (test 01) and gasoline PPC concept (test 02)

\begin{tabular}{lllll}
\hline & \multicolumn{2}{c}{ Test 01 - CDC } & \multicolumn{2}{c}{ Test 02 - PPC } \\
& CFD & Experiment & CFD & Experiment \\
\hline$C P L[d B]$ & 224.66 & 224.58 & 225.26 & 225.22 \\
ON $[d B]$ & 87.38 & 87.82 & 99.72 & 99.76 \\
$E_{\text {res }}\left[\right.$ bar $\left.^{2} \cdot s\right]$ & 0.78 & 2.05 & 1.68 & 1.17 \\
\hline
\end{tabular}

a)

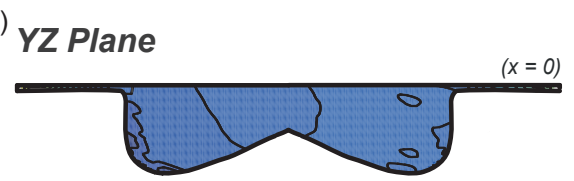

\section{XZ Plane}

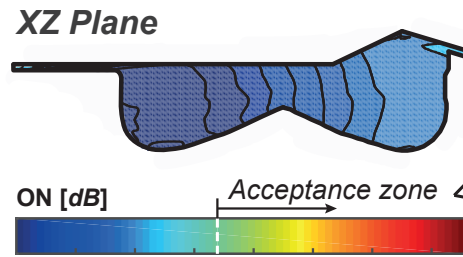

XY Plane

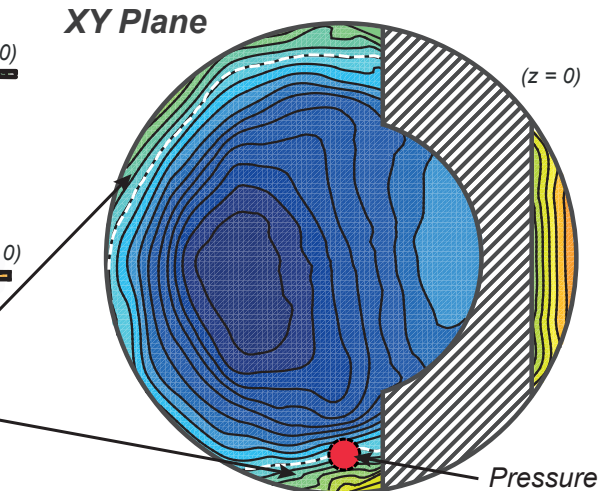

b)

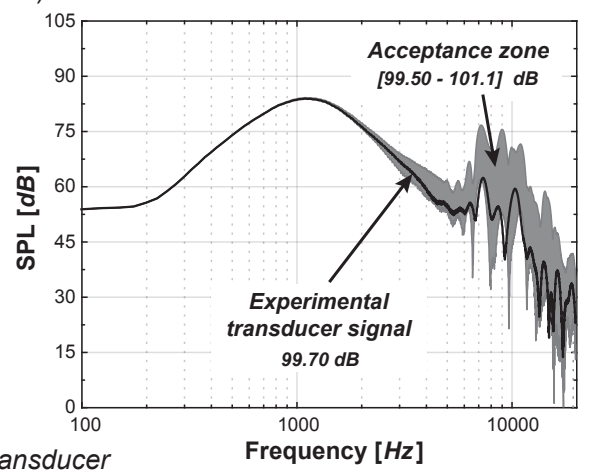

Figure 4: Validation of the in-cylinder pressure signal measured in the gasoline PPC reference case denoted as test 02. a) Variations of CFD calculated ON levels due to resonance in the combustion chamber, b) Differences in the spectra traces of the engine noise within the acceptance zone

a)

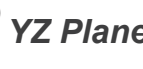

YZ Plane

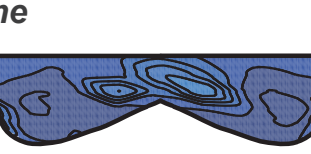

\section{XZ Plane}

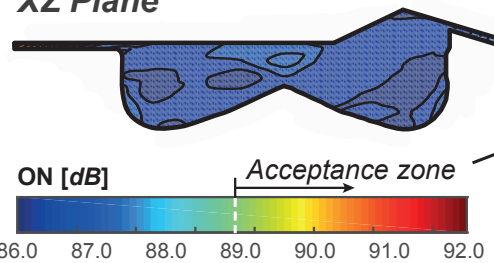

$(x=0)$
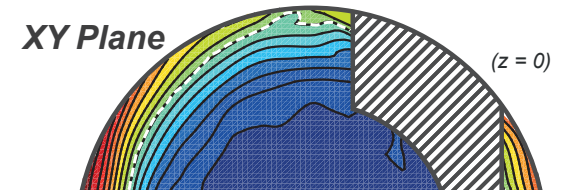

b)

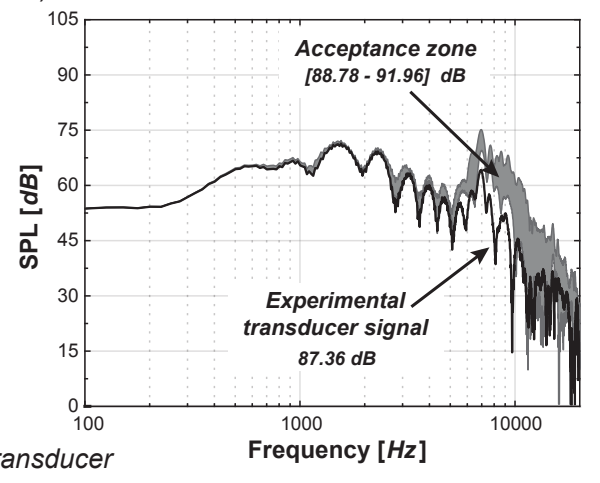

Figure 5: Validation of the in-cylinder pressure signal measured in the CDC case denoted as test 01. a) Variations of CFD calculated ON levels due to resonance in the combustion chamber, b) Differences in the spectra traces of the engine noise within the acceptance zone 
6 shows the effect of shifting the second injection timing on these parameters.

NOx and soot results confirm the well-known simultaneous reduction in both pollutants with the advance of SoE2 as a consequence of delaying the combustion after TDC. This allows decreasing local temperatures, thus disabling NO formation, while lengthening mixture time and avoiding high local equivalence ratio zones. However, $\mathrm{CO}$ increases due to the lower local temperatures that hinder its oxidation reaction to $\mathrm{CO}_{2}$ [24]. The low density conditions during early SoE2 also favor deeper spray penetration, and this results in more liquid fuel impinging onto the cylinder and piston surfaces. This fuel accumulation is the main source of unburned $\mathrm{HC}$ at the exhaust. So the simultaneous NOx and soot reduction is attained at the expense of decreasing combustion efficiency.

Comparing the cycle efficiencies, the indicated and combustion efficiencies follow the same trend -i.e. they decrease when advancing SoE2 events-, whereas the thermodynamic efficiency remains approximately constant. This indicates that the fraction of fuel that burns provides high thermal efficiency, but that it is not possible to burn all the injected fuel, due to the decrease in combustion efficiency. Hence, the best way to obtain high indicated efficiency levels and low emissions is to keep the combustion efficiency as high as possible while delaying combustion. In addition, combustion noise follows a trend similar to that of NOx and soot emissions: In sudden and short combustion conditions with high local temperatures, the emitted noise is higher than that generated by soft and long combustions with low local temperatures.

As a result of the above discussion, there appears to be a new trade-off between combustion noise and combustion efficiency, which limits the applicability of the gasoline PPC concept. Significant reductions in engine noise -almost $6 \mathrm{~dB}$ in two extreme cases- can be achieved with a limited impact on combustion efficiency. However, even with this potential reduction, the PPC concept ON levels are too high to fulfill noise emissions requirements. Further analyses are therefore performed to understand the combustion noise generation and later radiation.

\subsection{Comparative frequency analysis of $C D C$ and gasoline PPC concepts}

The main objective of this second analysis is the characterization of combustion noise in function of the most relevant parameters, starting with a comparative frequency study between CDC and gasoline PPC concepts.

Figure $7 \mathrm{a}$ shows the main differences between both combustion concepts in terms of spectra traces. This information is obtained using the most representative cycle among those recorded. It is evident that large deviations between both combustion concepts arise in the middle range of frequencies (201$2891 \mathrm{~Hz}$ ). The CDC concept shows lower SPL values in this frequency range than the gasoline PPC concept, which keeps a higher SPL up to $2891 \mathrm{~Hz}$. The SPL levels obtained with the gasoline PPC concept increase with the combustion rate due to the knocking trend. Slight differences may be observed in the high frequency range $(>2891 \mathrm{~Hz})$, where the CDC concept
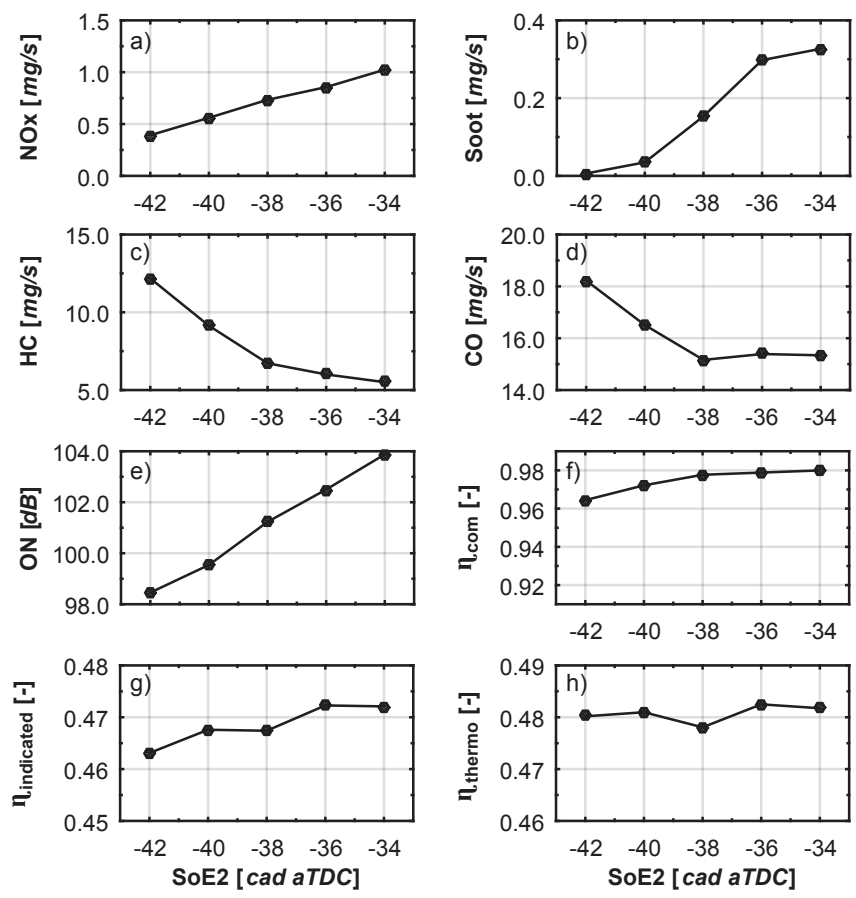

Figure 6: Influence of SoE2 on exhaust emissions (NOx, soot, $\mathrm{HC}$ and $\mathrm{CO}$ ), engine noise $(\mathrm{ON})$ and engine performance (combustion, indicated and thermodynamic efficiencies)

presents higher SPL than the gasoline PPC concept with early SoE2 values (up to -38 cad aTDC; tests 02,03 and 04). However, further SoE2 shifting towards the TDC eventually leads to the reverse situation, whereby the SPL in the gasoline PPC concept gets high values due to the excitation of additional oscillation modes.

Applying the in-cylinder pressure decomposition technique developed by Payri et al. [56], the spectra can be divided in three bands of frequency. As reported in the cited work, at low frequencies (in this case up to $201 \mathrm{~Hz}$ ) the content of the pressure signal is dominated by the pressure variation due to a compression and an expansion of simple phases without combustion. The medium frequencies are dominated by the combustion process, and the high frequencies are a consequence of the resonance in the combustion chamber.

Figures $7 \mathrm{~b}$ and $7 \mathrm{c}$ present a further study based on the use of this methodology to characterize the different bandwidths of frequencies. The first cut-off frequency applied to divide the spectra trace is obtained with the above technique, and the second cut-off frequency is fixed by the empirical function of Equation (7). In order to identify the contribution of each bandwidth to ON and CPL, it is interesting to note that the CPL can be evaluated in a specific bandwidth of frequencies according to Equations (9) and (10). In this way, the noise parameters can be related to their characteristic frequencies. Figure $7 \mathrm{~b}$ shows the relation between the maximum pressure time-derivative and the CPL evaluated in the medium range of frequencies, while Figure $7 \mathrm{c}$ links the energy of resonance and the CPL in the high frequency range (each of the characterization parameters has been normalized using its maximum value). The results ob- 


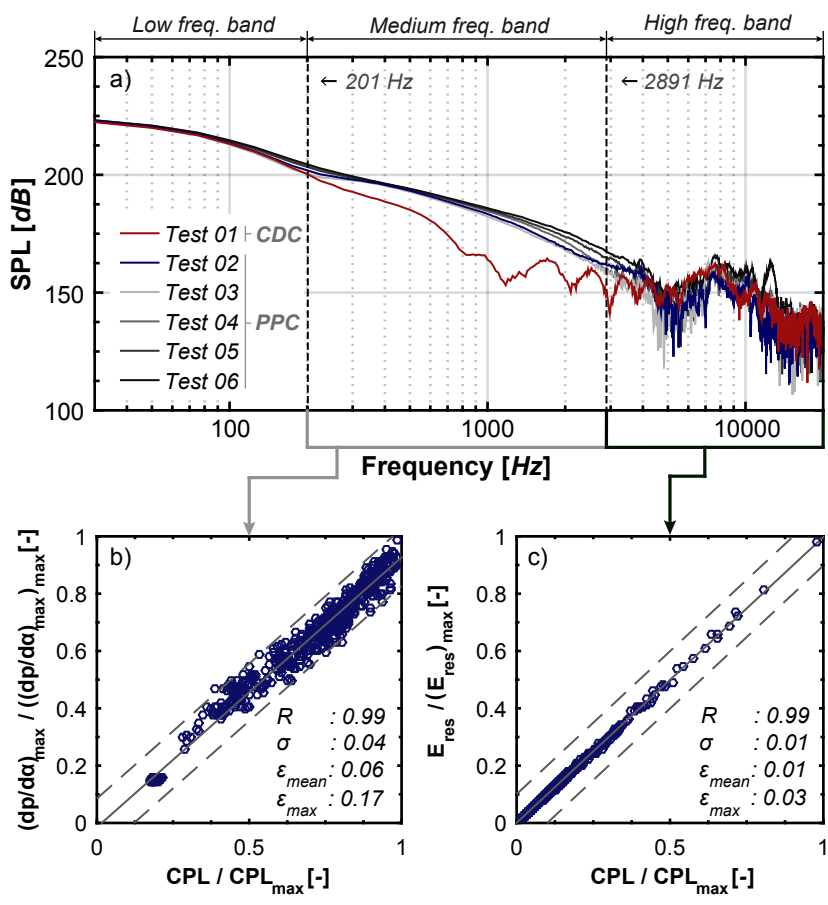

Figure 7: Frequency analysis of the CDC and gasoline PPC combustion concepts. a) In-cylinder pressure spectra traces comparison between both considered combustion concepts, b) Correlation between maximum pressure timederivative and CPL evaluated in the middle band of frequencies $(201-2891 \mathrm{~Hz})$, c) Correlation between the energy of the resonance and CPL evaluated in the high band of frequencies $(201-2891 \mathrm{~Hz})$

tained confirm that the maximum pressure time-derivative affects the CPL generated in the medium band of frequencies and the energy of resonance influences the CPL related to the high frequency band.

Figure 8 is included to analyze the influence of the SoE2 in $(d p / d \alpha)_{\max }$ and $E_{\text {res }}$ and to compare the gasoline PPC concept with the CDC concept. Both parameters tend to increase as the SoE2 is delayed towards the TDC. However, the maximum pressure time-derivative increases monotonically, whereas the energy of resonance evolution tends to be exponential. The comparison of these results with those obtained with the CDC concept shows that the significant differences observed in the medium range of frequencies are related to the important variations in maximum pressure time-derivative. When operating with the gasoline PPC concept, $(d p / d \alpha)_{\max }$ is one order of magnitude larger compared to that obtained when operating with the CDC concept even at earlier values of SoE2. The high RoHR generated by the gasoline PPC concept explains this fact, as indeed the pressure time-derivative is strongly influenced by this parameter [61]. On the contrary, lower local temperatures attained during the premixed combustion allow to reduce high frequency oscillations in the pressure profile until a certain SoE2 (-38 cad aTDC). However, additional shifts in SoE2 towards the TDC result in higher energy of resonance compared to the CDC concept.

At this point the combustion noise has been characterized by two parameters, but it is not possible to quantify the contri-
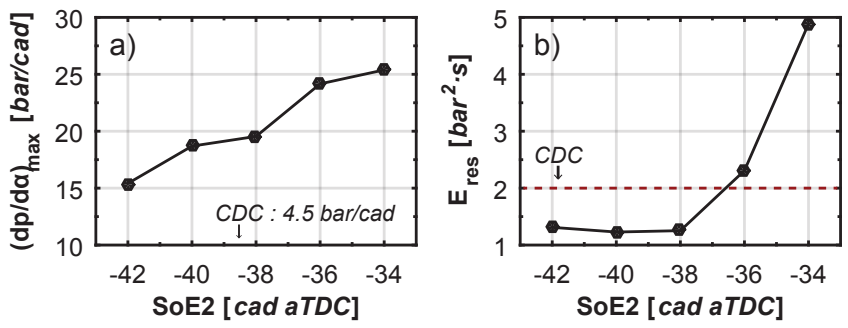

Figure 8: Influence of SoE2 on maximum pressure time-derivative and energy of resonance

bution of each one to the whole radiated noise without some further analysis. With this purpose, the ON was calculated at these bandwidths of frequencies and the results were normalized by the total ON level. Figures 9a and 9b compare the contribution of each frequency band to the calculated ON level and show the main differences in the engine noise spectra between both combustion concepts (test 01 and 02 ). The extremely different contribution of medium-high frequency bands to both combustion concepts is evident. In the CDC concept, the contributions to the ON level of the medium and high frequency bands are similar. In the gasoline PPC concept the $\mathrm{ON}$ is mainly influenced by the medium frequency band. It is therefore evident that the contribution of the resonance phenomena to the engine noise is almost negligible $(<5 \%)$ when operating with the gasoline PPC concept, while $(d p / d \alpha)_{\max }$ is the major influencing parameter in engine noise radiation. This feature has been observed in all tests with gasoline PPC concept, as seen in Figure 9c. For the $\mathrm{CDC}$ concept operation the maximum pressure time-derivative achieved is lower and it enhances the important influence of resonance on engine noise. Thus $E_{\text {res }}$ is the main determinant parameter for this type of engine operation. In addition, test 02 has a higher cycle-to-cycle dispersion than test 01 due to the ignition properties of the gasoline fuel.

In conclusion, the trade-off between engine noise and combustion efficiency is dominated by the maximum pressure timederivative and the $\mathrm{CO}-\mathrm{HC}$ emissions - as expressed by Equation (2). The main challenge lies in achieving the highest combustion efficiency while maintaining the maximum pressure timederivative as small as possible to control engine noise. The experimental results (Figure 6) evidence that a moderate reduction of ON levels is achievable by advancing the SoE2 event towards the compression stroke, but the target noise level of $87.38 \mathrm{~dB}$ is only achieved with earlier SoE2 timings. It is therefore interesting to extend the study to the analysis of the evolution of combustion efficiency with earlier SoE2.

\subsection{Analysis of extended operating range with CFD}

During the experimental tests the combustion stability was extremely deteriorated when advancing SoE2 beyond -42 cad aTDC to the point of reaching misfire conditions. The unfavorable gas thermodynamic conditions at these early SoE2, particularly in terms of pressure and temperature, increase both ignition delay and mixing time. As a result, local equivalence ratios tend to decrease down to very lean conditions, even achieving 
a)

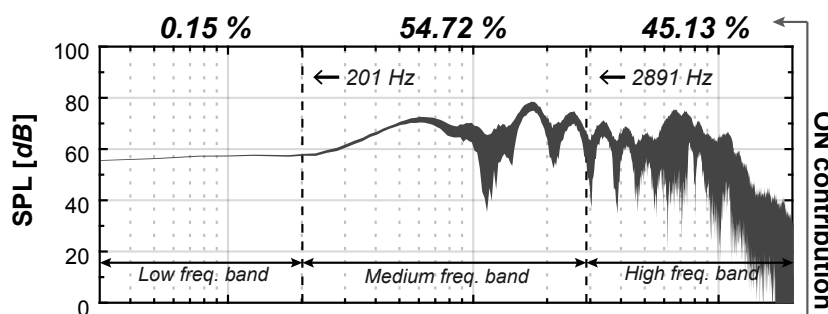

b)
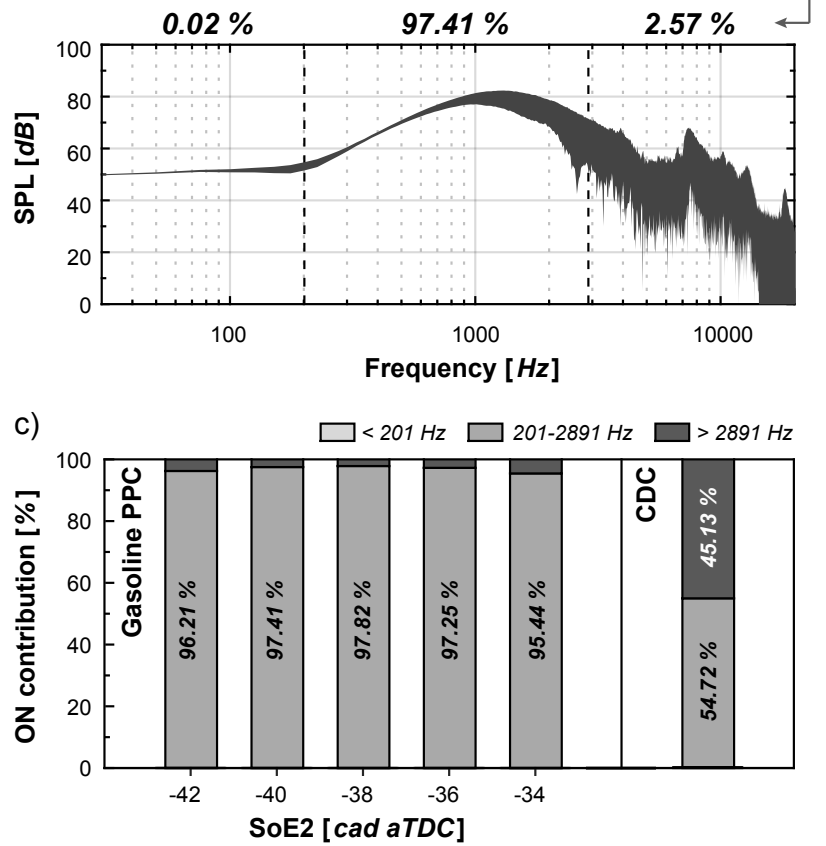

Figure 9: Contribution of each bandwidth of frequencies to ON level estimation. a) CDC concept (measurements of test 01 ) b) Gasoline PPC concept (measurements of test 02) c) SoE2 sweep in gasoline PPC concept
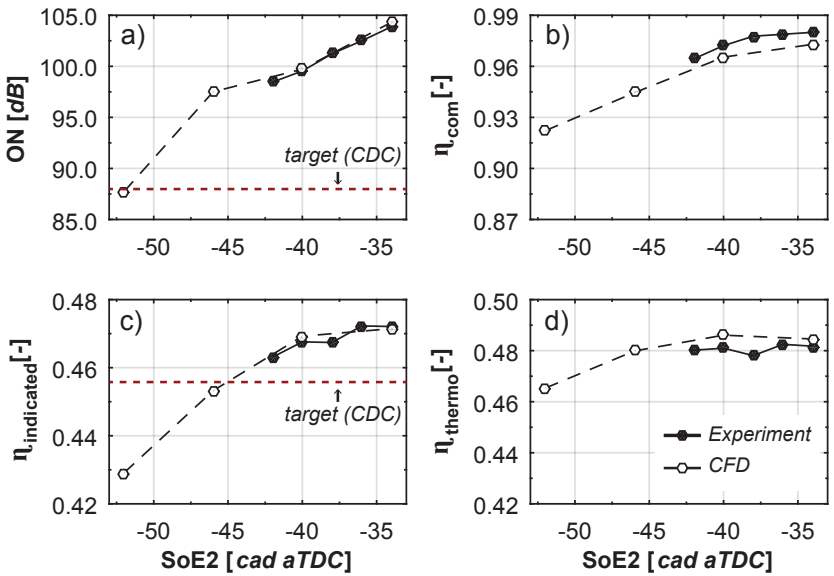

Figure 10: Impact of SoE2 on noise emissions $(\mathrm{ON})$ and engine performance (combustion, indicated and thermodynamic efficiency)

values below the ignition limit. This explains the deterioration in combustion stability and the misfiring observed experimentally. In order to complete the study and provide potential key paths for improving the results provided by the gasoline PPC concept, the numerical model described in Section 3 was used to extend the analysis to earlier SoE2.

In addition to the test 02 conditions used as reference case to validate the results predicted by CFD, Table 3 presents the three additional cases calculated to complete the study. Two of these cases, designated as test 07 and 08 respectively, were simulated to extend the SoE2 range to -46 cad aTDC and -52 cad aTDC. A third case with late SoE2, designated as test 06, is included to extend the SoE2 range to -34 cad aTDC and then beyond the knock-like combustion limit.

Both noise and efficiency results obtained from the SoE2 sweep described above are shown in Figure 10, where the suitable agreement between measured and numerically predicted results is evident, especially in $\mathrm{ON}$ and indicated efficiency. The slight differences in both combustion and thermodynamic efficiencies are caused by the disagreement in $\mathrm{CO}$ and $\mathrm{HC}$ levels described in Section 5.

As concluded from the first study presented in this section, $\mathrm{ON}$ reductions are achieved at the expense of engine efficiency losses. It is interesting to observe how decreasing the ON level down to the target -set on the basis of the equivalent running condition operating with the CDC concept- the indicated efficiency decreases to extremely low values, compromising the specific fuel consumption and consequently raising $\mathrm{CO}_{2}$ emissions. In addition, Figures $10 \mathrm{~b}$ and $10 \mathrm{~d}$ show that this reduction in the indicated efficiency is mainly related to the combustion process deterioration in the SoE2 range comprised between 46 and -34 cad aTDC. As the SoE2 is advanced beyond -46 cad aTDC, a secondary effect also contributes to the engine efficiency loss. In these cases the combustion takes place too late during the expansion stroke (see Figure 11a), producing less indicated work during the engine cycle and decreasing the thermodynamic efficiency. The impossibility to achieve a suitable agreement between both parameters - ON and indicated 

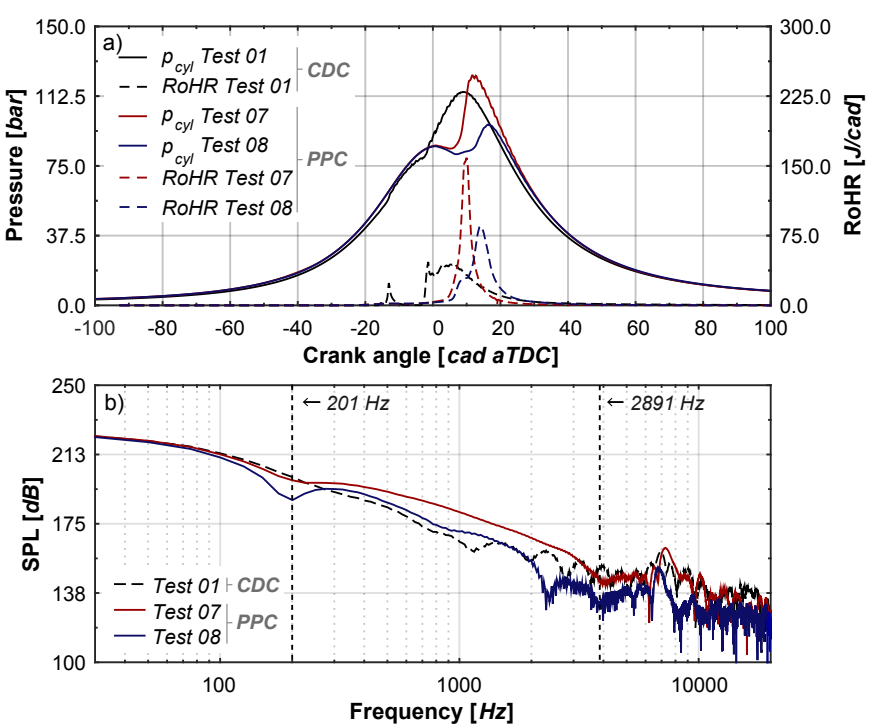

Figure 11: Comparison between CDC concept (CFD results of test 01) and early SoE2 timings in gasoline PPC concept (CFD results of tests 07 and 08 ). a) In-cylinder pressure and RoHR traces, b) In-cylinder pressure spectra traces

efficiency- is the main drawback limiting the implementation of the gasoline PPC concept in passenger car engines.

An analysis of the simulation results analogous to that previously performed using the experimental information is interesting in order to explore the limits of the gasoline PPC concept in terms of ON levels and indicated efficiency. Figure 11 compares the in-cylinder pressure from tests 01,07 and 08 in both time and frequency domains, while Tables 7 and 8 contain the two key parameters related to noise and also their relative contribution to the ON.

Since tests 01 (CDC) and 07 (PPC) have similar indicated efficiencies, they can be compared to evaluate the $\mathrm{ON}$ for both combustion concepts. Figure $11 \mathrm{~b}$ shows that previously reported trends of the spectra trace are kept. While the differences in the medium bandwidth of frequencies are significant $(\approx 7.72$ bar $/ \mathrm{cad})$, the variation in the energy of resonance is very small $\left(\approx 0.21 \mathrm{bar}^{2} \cdot s\right)$. Moreover, Table 8 also evidences the negligible contribution of this latter parameter on the $\mathrm{ON}(\approx 2.85 \%)$. As a result, the engine noise of the gasoline PPC concept remains at unacceptable levels $(97.5 \mathrm{~dB})$ if the indicated efficiency is fixed as $45.75 \%$ (test 01 ). Comparing tests 01 and 08, the ON level presents similar values in both combustion concepts. In test 08 there is simultaneous reduction of both characteristic combustion noise parameters, due to the lower SPL in the frequency range of $100 \mathrm{~Hz}$ to $20 \mathrm{kHz}$. This reduction is especially significant in the medium frequency band as a consequence of the notable drop in the maximum pressure time-derivative.

Finally, this analysis confirms the narrow relation between ON and RoHR. A less abrupt combustion process - characterized by smoother and longer RoHR profiles- results in lower combustion noise levels. The numerical simulations also confirm the trade-off trend between $\mathrm{ON}$ and combustion efficiency, namely the increase in $\mathrm{CO}$ and $\mathrm{HC}$ emissions as the combustion becomes less noisy.
Table 7: Noise parameters in CFD tests 01,07 and 08

\begin{tabular}{|c|c|c|}
\hline $\begin{array}{l}\text { Test } \\
{[-]}\end{array}$ & $\begin{array}{l}(\mathrm{dp} / \mathrm{d} \alpha)_{\max } \\
{[\mathrm{bar} / \mathrm{cad}]}\end{array}$ & $\begin{array}{l}E_{r e s} \\
{\left[b^{2} r^{2} \cdot s\right]}\end{array}$ \\
\hline 01 & 5.90 & 0.78 \\
\hline 07 & 13.62 & 0.99 \\
\hline 08 & 4.33 & 0.07 \\
\hline
\end{tabular}

Table 8: Contribution of each bandwidth of frequencies to $\mathrm{ON}$ level estimation in CFD tests 01, 07 and 08

\begin{tabular}{llll}
\hline Test & \multicolumn{3}{c}{ ON contribution [\%] } \\
{$[-]$} & $<201 \mathrm{~Hz}$ & $201-2891 \mathrm{~Hz}$ & $>2891 \mathrm{~Hz}$ \\
\hline 01 & 0.22 & 73.68 & 26.10 \\
07 & 0.02 & 97.13 & 2.85 \\
08 & 0.10 & 98.11 & 1.79 \\
\hline
\end{tabular}

\section{Conclusions}

An analysis of the combustion noise generated by a 2-stroke engine operated with the gasoline PPC concept has been presented in this paper. In order to select the most representative cycle -in terms of noise parameters- and preserving the high frequency information of the in-cylinder pressure signal, a statistical study based on minimized RMS was carried out. In addition, a novel methodology for the validation of combustion noise CFD results based on a frequency domain analysis has been defined, which has proven the ability of the model to reproduce adequately the combustion noise source. The significant influence of the experimental transducer location on combustion noise measurements has also been confirmed by the CFD calculations.

The validity of the combustion noise characterization based on the parameters $(d p / d \alpha)_{\max }$ and $E_{\text {res }}$ has been proven, allowing the comparison between the CDC and gasoline PPC concepts. Based on this, it may be concluded that the main contribution to the combustion noise radiation in the gasoline PPC concept comes from $(d p / d \alpha)_{\max }$ associated to the premixed combustion; whereas in the CDC concept the combustion noise radiation is dominated by both parameters, with a determinant contribution of the resonance phenomena. Consequently, it is meaningless to act on the resonance to reduce the combustion noise in the gasoline PPC concept, because it has been demonstrated that its contribution is irrelevant. On the contrary, a substantial noise reduction may be achieved by decreasing the maximum pressure time-derivative during the combustion.

The experimental results for the gasoline PPC concept have shown that it is possible to attain near zero levels of NOx and soot emissions while maintaining reasonable combustion efficiency values. However, the engine noise remains at unacceptable levels. Indeed, the trade-off between combustion noise and indicated efficiency has been evidenced by the experimental work presented here and confirmed by the CFD results. In summary, the viability of the gasoline PPC concept requires promoting quieter combustions through the establishment of smoother and longer RoHR traces, but these are associated to 
high losses in the combustion process.

\section{Acknowledgements}

The equipment used in this work has been partially supported by FEDER project funds "Dotación de infraestructuras científico técnicas para el Centro Integral de Mejora Energética y Medioambiental de Sistemas de Transporte (CiMeT), (FEDERICTS-2012-06)", framed in the operational program of unique scientific and technical infrastructure of the Spanish Ministerio de Economía y Competitividad

The authors kindly recognize the technical support provided by Mr. Pascal Tribotte from RENAULT SAS in the frame of the DREAM-DELTA-68530-13-3205 Project.

The authors want to express their gratitude to CONVERGENT SCIENCE Inc. and IGNITE3D Engineering GmbH for their kind support for performing the CFD calculations using CONVERGE software.

\section{Bibliography}

[1] E. G. Giakoumis, A. M. Dimaratos, C. D. Rakopoulos, Experimental study of combustion noise radiation during transient turbocharged diesel engine operation, Energy 36 (8) (2011) 4983 - 4995.

[2] J. A. Eng, Characterization of pressure waves in HCCI combustion.

[3] F. Bedford, C. Rutland, P. Dittrich, A. Raab, F. Wirbeleit, Effects of direct water injection on di diesel engine combustion.

[4] N. Samec, B. Kegl, R. W. Dibble, Numerical and experimental study of water/oil emulsified fuel combustion in a diesel engine, Fuel 81 (16) (2002) 2035 - 2044.

[5] G. Gonca, Investigation of the effects of steam injection on performance and NO emissions of a diesel engine running with ethanol-diesel blend, Energy Conversion and Management 77 (2014) 450 - 457.

[6] G. Gonca, B. Sahin, A. Parlak, Y. Ust, V. Ayhan, İdris Cesur, B. Boru, The effects of steam injection on the performance and emission parameters of a miller cycle diesel engine, Energy 78 (2014) 266 - 275.

[7] G. Kökkülünk, G. Gonca, V. Ayhan, İdris Cesur, A. Parlak, Theoretical and experimental investigation of diesel engine with steam injection system on performance and emission parameters, Applied Thermal Engineering 54 (1) (2013) 161 - 170.

[8] G. Kökkülünk, A. Parlak, V. Ayhan, İdris Cesur, G. Gonca, B. Boru, Theoretical and experimental investigation of steam injected diesel engine with EGR, Energy 74 (2014) 331 - 339.

[9] J. Benajes, S. Molina, R. Novella, E. Belarte, Evaluation of massive exhaust gas recirculation and miller cycle strategies for mixing-controlled low temperature combustion in a heavy duty diesel engine, Energy 71 (2014) $355-366$.

[10] G. Gonca, B. Sahin, A. Parlak, Y. Ust, V. Ayhan, İdris Cesur, B. Boru, Theoretical and experimental investigation of the miller cycle diesel engine in terms of performance and emission parameters, Applied Energy 138 (2015) $11-20$.

[11] G. Gonca, B. Sahin, A. Parlak, V. Ayhan, İdris Cesur, S. Koksal, Application of the miller cycle and turbo charging into a diesel engine to improve performance and decrease NO emissions, Energy 93, Part 1 (2015) 795 800.

[12] J. M. Desantes, J. Benajes, A. García, J. Monsalve-Serrano, The role of the in-cylinder gas temperature and oxygen concentration over low load reactivity controlled compression ignition combustion efficiency, Energy 78 (0) (2014) $854-868$.

[13] Y. Takeda, N. Keiichi, N. Keiichi, Emission characteristics of premixed lean diesel combustion with extremely early staged fuel injection, in: SAE Technical Paper, Vol. 961163.

[14] H. Ryo, Y. Hiromichi, HCCI combustion in a DI diesel engine, in: SAE Technical Paper, Vol. 2003-01-0745.
[15] W. L. Hardy, R. D. Reitz, A study of the effects of high EGR, high equivalence ratio, and mixing time on emissions levels in a heavy-duty diesel engine for PCCI combustion, in: SAE Technical Paper, Vol. 2006-010026 .

[16] A. J. Torregrosa, A. Broatch, A. García, L. F. Mónico, Sensitivity of combustion noise and NOx and soot emissions to pilot injection in PCCI diesel engines, Applied Energy 104 (0) (2013) 149-157.

[17] R. Hanson, D. Splitter, R. Reitz, Operating a heavy-duty direct-injection compression-ignition engine with gasoline for low emissions, in: SAE Technical Paper, Vol. 2009-01-1442.

[18] V. Manente, B. Johansson, P. Tunestal, W. Cannella, Effects of different type of gasoline fuels on heavy duty partially premixed combustion, SAE International Journal of Engines 2 (2) (2010) 71-88.

[19] M. Lewander, B. Johansson, P. Tunestål, Investigation and comparison of multi cylinder partially premixed combustion characteristics for diesel and gasoline fuels, in: SAE Technical Paper, Vol. 2011-01-1811.

[20] A. Austen, T. Priede, Origins of diesel engine noise, SAE Technical Paper 590127.

[21] O. Laget, C. Ternel, J. Thiriot, S. Charmasson, P. Tribotté, F. Vidal, Preliminary design of a two-stroke uniflow diesel engine for passenger car, in: SAE Technical Paper, Vol. 2013-01-1719.

[22] J. Benajes, R. Novella, D. De Lima, P. Tribotte, N. Quechon, P. Obernesser, V. Dugue, Analysis of the combustion process, pollutant emissions and efficiency of an innovative 2-stroke HSDI engine designed for automotive applications, Applied Thermal Engineering 58 (2013) 181-193.

[23] J. Benajes, S. Molina, R. Novella, D. De Lima, Implementation of the partially premixed combustion concept in a 2-stroke HSDI diesel engine fueled with gasoline, Applied Energy 122 (0) (2014) 94-111.

[24] J. Benajes, R. Novella, D. De Lima, P. Tribotte, Investigation on multiple injection strategies for gasoline PPC operation in a newly designed 2-stroke HSDI compression ignition engine, SAE Int. J. Engines 8 (2) (2015) 758-774.

[25] A. J. Torregrosa, A. Broatch, R. Novella, L. F. Mónico, Suitability analysis of advanced diesel combustion concepts for emissions and noise control, Energy 36 (2) (2011) 825-838.

[26] A. J. Torregrosa, A. Broatch, J. Martín, L. Monelletta, Combustion noise level assessment in direct injection diesel engines by means of in-cylinder pressure components, Measurement Science and Technology 18 (7) (2007) 2131-2142.

[27] F. Payri, A. Broatch, X. Margot, L. Monelletta, Sound quality assessment of diesel combustion noise using in-cylinder pressure components, Measurement Science and Technology 20 (1) (2009) 01-12.

[28] H. Liu, J. Zhang, P. Guo, F. Bi, H. Yu, G. Ni, Sound quality prediction for engine-radiated noise, Mechanical Systems and Signal Processing 56-57 (0) (2015) 277-287.

[29] K. Ohta, Y. Irie, K. Yamamoto, H. Ishikawa, Piston slap induced noise and vibration of internal combustion engines (1st report, theoretical analysis and simulation), SAE Technical Paper 870990.

[30] S. H. Cho, S. T. Ahn, Y. H. Kim, A simple model to estimate the impact force induced by piston slap, Journal of Sound and Vibration 255 (2) (2002) 229-242.

[31] V. Soloiu, E. Simons, M. Muinos, S. Harp, NVH of RCCI with DI ULSD and PFI 50\% N-Butanol, ICEF2015 1161.

[32] R. Hickling, D. A. Feldmaier, S. H. Sung, Knock-induced cavity resonances in open chamber diesel engines, Acoustical Society of America 65 (5) (1979) 1474-1479.

[33] Y. Ren, R. B. Randall, B. E. Milton, Influence of the resonant frequency on the control of knock in diesel engines, Proceedings of the Institution of Mechanical Engineers 213 (Part D) (1999) 127-133.

[34] L. Stanković, J. F. Böhme, Time-frequency analysis of multiple resonances in combustion engine signals, Signal Processing 79 (1) (1999) $15-28$.

[35] J. M. Desantes, A. J. Torregrosa, A. Broatch, Wavelet transform applied to combustion noise analysis in high-speed di diesel engines, SAE Technical Paper 2001-01-1545.

[36] J. Chang, M. Kim, K. Min, Detection of misfire and knock in spark ignition engines by wavelet transform of engine block vibration signals, Measurement Science and Technology 13 (7) (2002) 1108-1114.

[37] D. Anderton, Relation between combustion system and engine noise, SAE Technical Paper 790270.

[38] A. Ågren, r. Johansson, M. Klopotek, Noise reduction of diesel engines 
with internal stiffeners, Noise Control Engineering Journal 45 (1) (1997) $1-13$.

[39] P. Tribotte, F. Ravet, V. Dugue, P. Obernesser, N. Quechon, J. Benajes, R. Novella, D. De Lima, Two strokes diesel engine - promising solution to reduce $\mathrm{CO} 2$ emissions, Procedia - Social and Behavioral Sciences 48 (2012) 2295-2314.

[40] R. Payri, J. García, F. Salvador, J. Gimeno, Using spray momentum flux measurements to understand the influence of diesel nozzle geometry on spray characteristics, Fuel 84 (5) (2005) 551-561.

[41] R. Payri, F. J. Salvador, J. Gimeno, G. Bracho, A new methodology for correcting the signal cumulative phenomenon on injection rate measurements, Experimental Techniques 32 (1) (2008) 46-49.

[42] R. Christian, F. Knopf, A. Jaschek, W. Schindler, Eine neue messmethodik der bosch-zahl mit erhoehter empfindlichkeitl, Motortechnische Zeitschrift 54 (1993) 16-22.

[43] J. M. Desantes, J. Benajes, A. García, J. Monsalve-Serrano, The role of the in-cylinder gas temperature and oxygen concentration over low load reactivity controlled compression ignition combustion efficiency, Energy 78 (2014) $854-868$.

[44] F. Ihlenburg, The medium-frequency range in computational acoustics: Practical and numerical aspects, Journal of Computational Acoustics 11 (02) (2003) 175-193.

[45] M. Lapuerta, O. Armas, J. J. Hernández, Diagnosis of DI diesel combustion from in-cylinder pressure signal by estimation of mean thermodynamic properties of the gas, Applied Thermal Engineering 19 (5) (1999) 513-529.

[46] F. Payri, S. Molina, J. Martín, O. Armas, Influence of measurement errors and estimated parameters on combustion diagnosis, Applied Thermal Engineering 26 (2-3) (2006) 226-236.

[47] F. Payri, P. Olmeda, J. Martín, A. García, A complete OD thermodynamic predictive model for direct injection diesel engines, Applied Energy 88 (12) (2011) 4632-4641.

[48] A. Torregrosa, P. Olmeda, B. Degraeuwe, M. Reyes, A concise wall temperature model for DI diesel engines, Applied Thermal Engineering 26 (11-12) (2006) 1320-1327.

[49] V. Yakhot, S. Orszag, Renormalization group analysis of turbulence, Journal of Scientific Computing 1 (1) (1986) 3-51.

[50] C. Angelberger, T. Poinsot, B. Delhay, Improving near-wall combustion and wall heat transfer modeling in SI engine computations, SAE Technical Paper 972881.

[51] A. J. Torregrosa, A. Broatch, X. Margot, V. Marant, Combustion chamber resonances in direct injection automotive diesel engines: a numerical approach, Int. J. Engine Res. 5 (1) (2003) 83-91.

[52] B. Das Adhikary, Y. Ra, R. Reitz, S. Ciatti, Numerical optimization of a light-duty compression ignition engine fuelled with low-octane gasoline, SAE Technical Paper 2012-01-1336.

[53] J. Benajes, R. Novella, D. De Lima, P. Tribotté, Analysis of combustion concepts in a newly designed two-stroke high-speed direct injection compression ignition engine, International Journal of Engine Research 16 (1) (2015) 52-67.

[54] M. Jia, M. Xie, T. Wang, Z. Peng, The effect of injection timing and intake valve close timing on performance and emissions of diesel PCCI engine with a full engine cycle CFD simulation, Applied Energy 88 (9) (2011) 2967-2975.

[55] S. Fontanesi, G. Cicalese, A. d'Adamo, G. Cantore, A methodology to improve knock tendency prediction in high performance engines, Energy Procedia 45 (0) (2014) 769-778.

[56] F. Payri, A. Broatch, B. Tormos, V. Marant, New methodology for incylinder pressure analysis in direct injection diesel engines-application to combustion noise, Measurement Science and Technology 16 (2) (2005) $540-547$.

[57] L. Monelletta, Contribution to the study of combustion noise of automotive diesel engines, Ph.D. thesis, Universitat Politècnica de València (7 2010).

[58] L. J. Eriksson, Higher order mode effects in circular ducts and expansion chambers, The Journal of the Acoustical Society of America 68 (2) (1980) $545-550$.

[59] A. Broatch, X. Margot, A. Gil, C. Donayre, Computational study of the sensitivity to ignition characteristics of the resonance in DI diesel engine combustion chambers, Engineering Computations 24 (1) (2007) 77-96.

[60] A. Broatch, X. Margot, A. Gil, J. Donayre, A CFD approach to diesel engine combustion chamber resonance, SAE Technical Paper 2007-240043 .

[61] S. Rulik, W. Wróblewski, G. Nowak, J. Szwedowicz, Heat transfer intensification using acoustic waves in a cavity, Energy 87 (0) (2015) 21 30 .

\section{Nomenclature}

\begin{tabular}{|c|c|}
\hline \multicolumn{2}{|c|}{ List of symbols } \\
\hline$c$ & speed of sound $\left(m \cdot s^{-1}\right)$ \\
\hline$(d p / d \alpha)_{\max }$ & maximum pressure time-derivative $\left(\right.$ bar $\left.\cdot c a d^{-1}\right)$ \\
\hline$E_{\text {res }}$ & resonance energy $\left(b a r^{2} \cdot s\right)$ \\
\hline$f$ & frequency $(H z)$ \\
\hline$f_{c u t}$ & cut-off frequency $(\mathrm{Hz})$ \\
\hline$\dot{q}_{\text {exh }}$ & volumetric flow rate $\left(\mathrm{m}^{3} / \mathrm{s}\right)$ \\
\hline$m_{\text {fuel }}$ & fuel mass $(k g)$ \\
\hline$m_{C O}$ & $\mathrm{CO}$ mass $(k g)$ \\
\hline$m_{H C}$ & unburned HC mass $(k g)$ \\
\hline$n$ & engine speed $(r p m)$ \\
\hline$p_{\text {int }}$ & intake pressure (bar) \\
\hline$p_{c y l}$ & in-cylinder pressure (bar) \\
\hline$p_{\max }$ & maximum in-cylinder pressure (bar) \\
\hline$p_{\text {rail }}$ & injection rail pressure (bar) \\
\hline$t$ & time $(s)$ \\
\hline$u$ & flux velocity $\left(m \cdot s^{-1}\right)$ \\
\hline$x$ & cell size $(m)$ \\
\hline$\eta_{c o m b}$ & combustion efficiency (\%) \\
\hline$\eta_{\text {indicated }}$ & indicated efficiency (\%) \\
\hline$\eta_{\text {thermo }}$ & thermodynamic efficiency $(\%)$ \\
\hline$\epsilon_{r}$ & relative error $(\%)$ \\
\hline \multicolumn{2}{|c|}{ Sub-and Superscripts } \\
\hline \multicolumn{2}{|c|}{$C F D$ related to simulation } \\
\hline \multicolumn{2}{|c|}{ related to cylinder } \\
\hline \multicolumn{2}{|r|}{ xperimental measurements } \\
\hline \multicolumn{2}{|c|}{ maximum value } \\
\hline \multicolumn{2}{|c|}{ mean averaged value } \\
\hline \multicolumn{2}{|c|}{ minimum value } \\
\hline \multicolumn{2}{|l|}{ rep } \\
\hline \multicolumn{2}{|l|}{ res } \\
\hline \multicolumn{2}{|l|}{ trans } \\
\hline
\end{tabular}




\section{List of abbreviations}

$\begin{array}{ll}\text { AMR } & \text { adaptive mesh refinement } \\ \text { aTDC } & \text { after Top Dead Center } \\ \text { CA50 } & \text { crank angle for 50\% of fuel burnt } \\ \text { cad } & \text { crank angle degree } \\ \text { CDC } & \text { Conventional Diesel Combustion } \\ \text { CFD } & \text { Computational Fluid Dynamics } \\ \text { CI } & \text { compression ignition } \\ \text { CPL } & \text { cylinder pressure level } \\ \text { DI } & \text { direct injection } \\ \text { DPF } & \text { Diesel Particulate Filters } \\ \text { EGR } & \text { exhaust gas recirculation } \\ \text { EVC } & \text { exhaust valve closing (angle) } \\ \text { EVO } & \text { exhaust valve opening (angle) } \\ \text { FSN } & \text { Filter Smoke Number } \\ \text { HCCI } & \text { homogeneous charge compression ignition } \\ \text { HSDI } & \text { high speed direct ignition } \\ \text { IMEP } & \text { indicated mean effective pressure } \\ \text { IVC } & \text { intake valve opening (angle) } \\ \text { IVO } & \text { intake valve opening (angle) } \\ \text { LHV } & \text { lower heating value } \\ \text { LNT } & \text { Lean Nox Trap } \\ \text { LTC } & \text { low temperature combustion } \\ \text { ON } & \text { overall noise } \\ \text { PM } & \text { particulate matter } \\ \text { RMS } & \text { root mean square } \\ \text { PPC } & \text { Partially Premixed Combustion } \\ \text { PRF } & \text { Primary Reference Fuel } \\ \text { RoHR } & \text { rate of heat release } \\ \text { RON } & \text { Research Octane Number } \\ \text { SCR } & \text { Selective Catalytic Reduction } \\ \text { SI } & \text { spark ignition } \\ \text { SoE } & \text { start of energizing (angle) } \\ \text { SPL } & \text { sound pressure level } \\ \text { TDC } & \text { Top Dead Center } \\ \text { VVT } & \text { Variable Valve Timing } \\ & \end{array}$

